\begin{tabular}{lllllllllllllllllllllllllllllllll}
\hline$R$ & $E$ & $V$ & I & S & T & A & D & E & E & S & T & U & D & I & O & S & I & N & T & E & R & N & A & C & I & O & N & A & L & E & S
\end{tabular}

\title{
Impacto de la ampliación hacia el Este de la Unión Europea: convergencia y estabilidad
}

\author{
Dr. José Ramón García Menéndez
}

La ampliación de la UE es uno de los próximos desafios a los que se enfrenta Europa. Es un tema muy amplio y en el que existe diversidad de opiniones sobre sus efectos e implicaciones, sobre las medidas que deberían llevarse a cabo, sobre las condiciones de las negociaciones, la políticas que se deben aplicar, las reformas a realizar, etc. En este artículo pretendemos, en la medida de lo posible, hacer una síntesis de la evolución del proceso de ampliación, desde la situación en que se encontraban los países candidatos hasta las últimas negociaciones de cara a la próxima adhesión.

En la primera sección se analizan algunos de los efectos de la ampliación, haciendo especial hincapié en aquellos temas de mayor controversia, como la financiación, la agricultura o los flujos migratorios. En la siguiente, se examina el avance de las negociaciones con los países candidatos, y al mismo tiempo se comentan algunas cuestiones que podrían influir en la convergencia y la estabilidad del proceso. Y por último, se repasan las implicaciones de la ampliación para terceros países.

I. EL IMPACTO DE LA AMPLIACIÓN

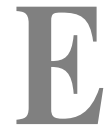

n la última década se han producido cambios fundamentales en la economía y el sistema político de los países candidatos a la ampliación. En cierta medida el proceso de transición de los países ex comunistas desde un sistema de planificación centralizada hacia un sistema democrático está asociado con las relaciones que mantienen con la UE, ya que ésta ha apoyado, dirigido e impulsado a estos países en el proceso de transición, y es un importante medio para asegurar los progresos logrados en estos países. 
La Comisión Europea asegura que, bien dirigida la ampliación traerá consigo importantes beneficios, tanto para los actuales miembros de la Unión como para los aspirantes a unirse a ella ${ }^{1}$. Algunos de los beneficios ya son visibles:

- La aparición de democracias estables en Europa oriental y central, con instituciones democráticas y el incremento del respeto por las minorías.

- Las reformas económicas han permitido conseguir que esos países alcancen un elevado grado de crecimiento económico.

- El proceso se ha acompañado de estudios y análisis hechos por la UE y también por ayuda financiera, apreciándose ya algunos resultados.

- Como resultado de la unión se disfruta de un crecimiento del comercio de la UE con esos Estados, lo que genera crecimiento y empleo en los países miembros.

La Comisión señala, además, otros beneficios que derivan de la ampliación, como la extensión de la paz, estabilidad y prosperidad en Europa, que conllevan un mejoramiento del nivel de vida de ciudadanos dentro y fuera de la Unión. Si los países miembros adoptan las políticas que se están aplicando en la UE, aumentará el nivel de protección medioambiental y la lucha contra el crimen, las drogas, la corrupción y la inmigración ilegal. Además, su incorporación enriquecerá la diversidad cultural, el intercambio de ideas y el entendimiento con otros pueblos. La
Comisión también señala las ventajas que acarreará el fortalecimiento de la posición de la UE en el mundo, tanto en cuestiones económicas, como de seguridad política, de comercio internacional y otros campos afectados por los efectos de la globalización.

\section{La ampliación de la UE enriquecerá la diversidad cultural, el intercambio de ideas y el entendimiento con otros pueblos.}

Sin embargo, aunque indudablemente la ampliación tendrá efectos beneficiosos, existen mucha incertidumbre al respecto, ya que las reformas económicas no avanzan con la misma velocidad en todos los países candidatos, y aún quedan cuestiones importantes por hacer. Por otra parte, la estrategia de adhesión no está claramente definida y todavía hay aspectos que concretar para aceptar a los países candidatos. En este apartado intentaremos presentar la situación de algunas materias de crucial importancia para el proceso de ampliación, como son la inversión, el movimiento de personas, el comercio, la agricultura y la financiación.

\section{INVERSIÓN EXTRANJERA DIRECTA}

Desde que comenzaron las reformas políticas y económicas en los países de

${ }^{1}$ En la página web de la Ampliación de la UE se encuentran los principales argumentos para la ampliación: http://www.europa.eu.int/comm/enlargement/arguments/index.htm. 
Europa central y del este, países miembros de la UE están realizando allí importantes inversiones. Para los PECO este traspaso de capital supone una ayuda fundamental para la reestructuración económica, ya que además se transferirá tecnología y conocimiento, con lo cual el proceso de reforma será mucho más rápido. Así, los flujos de capital han contribuido significativamente a incrementar la capitalización, aliviando la situación financiera del capital doméstico en los PECO, con importantes repercusiones en el crecimiento económico. Con la integración en la UE se espera que estos flujos aumenten, como ha sucedido en ampliaciones anteriores, por lo que se espera que el desarrollo de estos países sea todavía mayor una vez que se hayan incorporado a la UE.

Pero no todos los efectos de la inversión son positivos, ya que a menudo la IED trae consigo algunos efectos que pueden ser negativos para la economía nacional, debido a que pueden dañarse los incentivos nacionales o regionales, impidiendo la creación o desarrollo de estructuras económicas nacionales, pues muchas de estas inversiones son realizadas por empresas multinacionales, altamente competitivas y eficientes que impiden la emergencia o el desarrollo de otras alternativas procedentes de capitales nacionales. Además, debe tenerse en cuenta que el capital no busca la igualdad y la cohesión económica y social, sino su propio interés, por lo que tiende a centrarse en determinadas zonas económicas en que obtiene mayor rendimiento y discriminar a otras regiones o países que también necesitan de financiación.

\section{El capital no busca la igualdad sino su propio interés.}

Los principales receptores de IED entre los PECO son Hungría, la República Checa y Polonia, todos ellos países que estaban considerados en el primer grupo de candidatos a la ampliación en el Consejo de Luxemburgo. Esta situación provocará una doble causalidad: la estabilidad de estos países hace que hayan sido incluidos antes que otros en el grupo de candidatos a la adhesión, pero a la vez esta inclusión influye en la credibilidad de su política y de sus instituciones frente a los inversionistas, lo que a su vez les dará mayor prosperidad.

El cuadro (ver en Anexos) revela la gran diferencia del porcentaje de flujos entre los tres primeros receptores de capital y los siguientes. Al parecer, esta tendencia no cambiará con la adhesión, al menos a corto y mediano plazos, aunque es posible que la integración suponga mayor estabilidad política y mayor crecimiento económico, con lo cual incluso los países más rezagados empezarían a ser atractivos.

\section{Flujos Migratorios}

Hasta ahora, el libre movimiento de personas ha sido uno de las negociaciones más restrictivas que impone la UE a los países candidatos, ya que salvo algunas cláusulas suscritas bilateralmente en 
tre algunos países ${ }^{2}$, no se permite la libre circulación de personas. En su informe sobre los movimientos de trabajadores (marzo 2001) la Comisión Europea afirma que éste será uno de los últimos temas a tratar en las negociaciones. Además, se considera que la ampliación de la UE a los países candidatos no supondrá directamente el libre intercambio de personas, sino que, al igual de lo sucedido con España y Portugal, donde el proceso tardo seis años, se hará gradualmente. En la ampliación se prevé también un comportamiento similar y, además, posiblemente la transición se aplique diferenciando entre países, regiones, sectores y duración. En este sentido, es necesario crear un plan claramente definido, que incluya los pasos a seguir y las políticas a aplicar tanto por la UE como por los países candidatos, aunque de momento este trabajo está por hacerse.

\section{Al igual que el caso de España y Portugal, el libre intercambio de personas será un proceso gradual.}

El factor más importante relacionado con la migración de trabajadores es la diferencia entre los salarios y la situación laboral de los países candidatos y los países miembros. También influyen la tradición migratoria, la existencia de problemas étnicos o políticos, las diferencias culturales y lingüísticas, la distancia geográfica, la evolución de la economía y del progreso social, etc. Aunque en estos países, el mayor factor es, sin duda, la diferencia de salarios y el elevado nivel de desempleo.

Los pronósticos acerca de los movimientos de trabajadores varían considerablemente según diferentes autores, de acuerdo con la metodología y las hipótesis iniciales, pero en general los estudios sobre el tema indican que no se producirá un incremento espectacular de la inmigración.

El informe de la Comisión (marzo 2000) sobre el movimiento de trabajadores indica que uno de los estudios más minuciosos y fiables es el Brücker y Boeri (2000), al que pertenece el siguiente gráfico (en Anexos).

Este estudio confirma que el impacto en el mercado de trabajo de la UE tiene que limitarse, ya que aunque no afectaría en gran medida a los salarios y al empleo en la media de la UE, es importante señalar que los inmigrantes se concentrarían sólo en un pequeño número de países. Alemania absorbería dos tercios de la población, cerca de unos 45.000 trabajadores por año y Austria sería el segundo en recibir inmigrantes, con un $10 \%$ del flujo total, es decir, más de 8.000 trabajadores por año. Por tanto, sería principalmente un problema para los países más próximos y con mejores perspectivas económicas, como Alemania y Austria.

${ }^{2}$ Una excepción común es el empleo de trabajadores temporales, como por ejemplo trabajadores estacionales. Alemania ha firmado un gran número de acuerdos bilaterales con países candidatos según informe de la Comisión (de marzo de 2001), y ya tiene cerca de 230.000 extranjeros provenientes de los países candidatos. 
Uno de los aspectos que últimamente aparece relacionado con la migración es el envejecimiento de la población europea. Según un estudio de las Naciones Unidas (2000) se recoge que, ceteris paribus, una media de la migración neta de 1.4 millones de personas por año ayudaría entre 1995 y 2050 a mantener estable la población trabajadora de la UE. En muchos países candidatos la población de 20 a 35 años crecerá en la próxima década, por lo que el trasvase de esta población joven hacia la UE podría ayudar a soportar el peso de la seguridad social y mantener el nivel de población activa en un nivel similar.

\section{El trasvase de población joven hacia la UE podría ayudarla a mantener el nivel de población activa.}

\section{El COMERCIO}

Desde comienzos de los noventa los países del este empezaron a orientar sus lazos económicos hacia la UE. En el proceso de transición, se aplicaron medidas para liberalizar el comercio interno y poder soportar el comercio internacional, eliminar las restricciones y barreras internacionales, introducir tipos de cambio convertibles a monedas internacionales, etc. Se empezaron a crear Acuerdos de Libre Comercio, que contemplaban medidas excepcionales para los países más avanzados (Hungría, Polonia y República Checa), incluían la cláusula de nación más favorecida, y eliminaban al- gunas de las restricciones cuantitativas a las importaciones procedentes de estos países. Sin embargo, seguían aplicándose restricciones a la importación de los productos más "sensibles" hacia la UE, que en los países candidatos continuaban estando protegidos.

El volumen de comercio entre los países candidatos a la adhesión y los miembros de la UE experimentó un considerable incremento desde principios de los años 90. En 1998, la exportaciones de la UE a los PECO eran, en promedio, unas siete veces más elevadas que en 1990, y las importaciones se habían quintuplicado (C. Weise, J, Bachtler, 2001). Alemania es con mucho el país que más negocios realiza con los PECO, ya que representa cerca del $50 \%$ del total de las transacciones europeas con estos países. Esto puede verse en el cuadro que figura a continuación, en que aparecen las importaciones y exportaciones de los países miembros de la UE con los países candidatos, en miles de millones de euros (ver en Anexos).

La proximidad geográfica juega aquí un importante papel, al igual que en las inversiones y en el movimiento de trabajadores, y una vez más Alemania es uno de los afectados por este factor, pues mantiene fuertes vínculos con los países de Europa central. Los países del sur de Europa, como Italia y Grecia, aumentarán sus relaciones con los países balcánicos, mientras que Europa del Norte (Dinamarca, Finlandia y Suecia) lo harán con los países bálticos.

En cuanto a los países no pertenecientes a la UE, los mismos que se declaraban en los apartados anteriores consegui- 
rán un mayor nivel de comercio con la Unión. Polonia, Hungría y la República Checa son los mayores importadores y exportadores de bienes y servicios a la UE, seguidos de Turquía. En el año 2000, siguiendo la misma referencia anterior tenemos las siguientes cantidades en miles de millones de euros (ver en Anexos).

Respecto de la estructura del intercambio realizado, siguiendo a C. Weise, J, Bachtler, Downes, McMaster y Toepel (2001), la UE se especializa en productos de elevado precio y en segmentos productivos con alta calidad, que necesitan un alto contenido de capital humano y de Investigación y Desarrollo, mientras que los PECO se especializan en productos de bajo precio y buscan segmentos de mercado de bajo contenido en capital humano y de investigación y desarrollo. Dentro de estos países Hungría es el que más se está moviendo hacia segmentos de mayor nivel de tecnología y desarrollo. Otros países como Polonia, Bulgaria y Rumania, tienden a concentrarse más en bienes de alto coeficiente de mano de obra y menos habilidad productiva.

\section{Agricultura}

La ampliación convertirá a la UE en la primera potencia agrícola mundial. En general, la agricultura ocupa, tanto en términos del PIB como de empleo, un lugar más importante en los PECO que en la UE de los quince. Según el informe del Commissariat Général du Plan a la Asamblea francesa (1999), alrededor del 22\% de la población activa de los PECO tra- baja en el sector agrícola, frente a menos del $5 \%$ en la UE-15. Sin embargo, existen fuertes disparidades entre estos países; ya que Polonia y Rumania son los que tienen mayor peso en la agricultura.

A principios de los años noventa, este importante potencial agrícola cuya producción se asemejaba mucho a la de la UE (frutas, legumbres y ganadería bovina, porcina y avícola) y que ya tenía problemas de excedentes, hizo que ésta temiera una posible invasión, pues se produciría una competencia de productos entre ambas regiones y aumentarían los stocks. Sin embargo, al examinar las actuales transacciones agroalimentarias entre ambas se comprueba que no es así, pues, con la excepción de Hungría y Bulgaria, la balanza comercial agroalimentaria de los PECOS con la UE es deficitaria, con la UE, y lo es desde 1990. Hay que considerar que todavía hay restricciones al ingreso de algunos productos agrícolas en la UE, tema que se está tratando con vistas a la próxima ampliación en 2004. Además, los países candidatos piden que se reduzcan las ayudas a ciertos productos que importan de la UE. Para no sufrir consecuencias traumáticas ante la próxima adhesión es preciso acelerar el proceso de convergencia en este tema.

\section{En la UE subsisten restricciones al ingreso de algunos productos agrícolas.}

Respecto de la competitividad agrícola de los PECO, hay diversas opiniones. Algunos autores piensan que podrían 
ser más competitivos que los actuales miembros debido a la tradición agrícola, al bajo coste de las tierras y a la abundancia de mano de obra en la agricultura. Sin embargo, otros estiman que en el mejor de los casos su competitividad se igualaría a la de la UE, para lo cual requerirían financiación. Y éste es su gran problema, pues necesitan un elevado nivel de financiación para poder competir con la producción agrícola de los quince.

La financiación es un tema importante, debido a que estos países necesitan de una fuerte suma para reformar las estructuras agrarias que heredaron del sistema comunista. En el período de preadhesión, el mecanismo principal de ayuda es la SAPARD, y una vez que los países candidatos se integren a la UE participarán de la PAC (Política Agraria Común). Con la ampliación de la UE, la PAC debe reformarse, ya que la introducción de estos países como partícipes de la actual política supondría un elevado gasto financiero para la UE. En enero de este año, la Comisión Europea aprobó un informe en el que se considera mejor reducir los pagos directos a los agricultores y ganaderos que contempla la actual política, limitándolos al 25\% del nivel que se paga actualmente a los países miembros, hasta llegar a $100 \%$ en 10 años. El argumento de la Comisión es que los pagos directos a los agricultores o granjeros podría dañar sus propias sociedades, debido a que se enriquecerían relativamente respecto de otros trabajadores que participan en el mercado laboral nacional. Con esta ley, países como España, pese a ser dos veces más rico que Polonia, recibirá mucho más ayu- da que éste. Pero, el temor radica en que si se conceden ayudas directas, se paralizarán las reformas. Sin embargo países como Alemania, el Reino Unido o los Países Bajos, están asumiendo el costo de lo que podría ser dinero mal gastado, o al menos, no debidamente invertido. Entonces, la UE propone intensificar la ayuda financiera mediante una política reforzada de desarrollo rural. No obstante, los países miembros tendrán acceso directo a las medidas de mercado de la PAC, con el fin de obtener el libre intercambio de productos agrícolas.

\section{La Comisión estima que los pagos directos a los agricultores podrían dañar sus propias sociedades.}

\section{LA FINANCIACIÓN}

La incorporación de los países candidatos plantea un amplio conjunto de necesidades de apoyo financiero debido al elevado peso que en casi todos ellos tienen las actividades agrarias, a los problemas de reconversión industrial pendientes y, sobre todo, al hecho de que su ingreso por habitante es muy inferior a la media comunitaria (que en su conjunto representa un $40 \%$ de dicha media expresada en Paridades del Poder de Compra). Además hay otras necesidades en diversos frentes que también requerirán ayudas que faciliten una rápida adaptación a la Comunidad. 
La PAC y la Política de Cohesión Económica y Social serán los dos fondos y programas con mayor apoyo financiero para la ampliación. Durante el período 2000-2006, los países candidatos tienen cabida en ellos, incluso en la fase previa a su adhesión, por lo que participará, no sólo de la ayuda a la preadhesión, sino también en las políticas propias de los Estados miembros, entre ellas las ya mencionadas. Respecto de la PAC, ya hemos comentado que se aplicará en forma gradual, en cuanto a la política de cohesión, es sabido que el bajo nivel de ingreso per cápita de los PECO las convertiría automáticamente en regiones objetivo 1 de las acciones estructurales de la UE. Por otra parte, en las actuales situaciones financieras el presupuesto comunitario tampoco está en condiciones de acometer de golpe las actuaciones que en este ámbito comportaría su plena integración. Por tanto, al igual que con la PAC, se impone la gradualidad.

El problema es que en las Perspectivas Financieras 2000-2006 domina una política de rigor presupuestario, lo que dificulta un tanto la compatibilidad del proceso de ampliación con el adecuado desarrollo de otras políticas comunitarias, entre ellas la de cohesión económica y social. El rigor presupuestario se concreta en el hecho de que el límite máximo de recursos propios para el período es el 1,27\% del PIB comunitario. A partir de ahí, se ha producido un cambio sensible en la estructura del gasto con relación a las Perspectivas Financieras anteriores, reduciéndose de manera apreciable de los gastos estructurales. En palabras de Juan R. Cuadro
(2002) "el tope fijado al monto total de los presupuestos comunitarios -el 1,27\% del PIB total-aparece como un auténtico freno a la línea expansiva que se dibujó anteriormente y constituye un techo realmente bajo para atender las necesidades de una UE que aceptará nuevos países miembros".

Es cierto que los países candidatos irán aumentando progresivamente su participación en el conjunto de la UE hasta alcanzar algo más de un $17 \%$ del presupuesto comunitario en el 2006. Siendo entonces los fondos estructurales los que obtendrán un mayor reparto, con cerca del 12,28\% del presupuesto total del 2006, al mismo tiempo que los miembros de la UE-15 irán disminuyendo su participación relativa en el conjunto de los Fondos Estructural y de Cohesión, de 34\% en el 2000 hasta 27,2\% en 2006 (datos tomados de Juan R. Cuadro 2002). A partir del 2006 se aplicarán nuevos presupuestos, que todavía están por elaborarse, y es a partir de ese año cuando se espera que los países candidatos participen realmente como plenos miembros de la ayuda financiera, ya que aunque necesitan más de ella que los actuales miembros, y aunque se integren en la UE en 2004, no tendrán pleno acceso a los fondos comunitarios al menos hasta 2006, y aún así no con certeza, ya que todavía no se elaboran esos presupuestos no están aun elaborados.

\section{El desarrollo de la política de cohesión económica y social se dificulta por la política de rigor presupuestario}




\section{Convergencia y eStabilidad} ANTE LA AMPLIACIÓN

La UE ve su expansión al este sobre todo como una oportunidad para extender la paz y la estabilidad al continente.

\section{El cumplimento de los criterios de Copenhague}

Para comprobar los avances logrados por los países candidatos a la adhesión examinaremos los resultados que la Comisión ha indicado en el informe periódi$\operatorname{co}^{3}$ del año 2000, que es el anual publicado. Se analizan cada uno de los 29 capítulos de acervo de la UE, comprobando los progresos realizados por cada uno de los candidatos para adoptar el acervo y garantizar su puesta en vigor.

\section{Criterios políticos}

Actualmente todos los países, excepto Turquía, cumplen con los criterios políticos de Copenhague, ya tienen sistemas democráticos de gobierno y celebraron elecciones libres y transparentes, y además en todos los países se ha conseguido un fortalecimiento democrático. Sin embargo, en general hay que avanzar más en la lucha contra la corrupción en la administración pública, que se debe posiblemente a los escasos salarios del sector y a la utilización de controles burocráticos en la economía, aunque en este sentido ha avanzado a pese a que persiste el problema. Otro punto en el que se deben tomar medidas es en el tráfico de mujeres y ni$\tilde{n} o s$, que es cada vez mayor, sin indicios de mejoras.

\section{Hay que avanzar más en la lucha contra la corrupción en la administración pública.}

El informe hace especial hincapié en Turquía, señalando que todavía tiene mucho que avanzar en materia de derechos humanos y las libertades fundamentales, como por ejemplo en limitar la pena capital. De todas formas, se comprueban avances en la libertad de expresión y comunicación, libertad de prensa y libertad de asociación.

Sin embargo, el informe nada dice de los problemas respecto de la división de Chipre entre griego-chipriotas al sur y turco-chipiotras al norte del país. Si la primera es admitida en la UE, se teme la reacción turca; en cambio si tampoco se admite la parte griego-chipriota, la UE tendría problemas con Grecia, que apoya incondicionalmente la adhesión de Chipre y que en caso de no ser admitidos, podrían vetar la ampliación. Ante esta perspectiva "la UE, por su parte, está esperando contra cualquier esperanza, que el final de las negociaciones con la República de Chipre, obligará finalmente a los griego-chipriotas y turco-chipriotas a negociar el acuerdo para permitir que la unión admita a una isla unida y pacífica. En otras palabras, más que exacerbar la

${ }^{3}$ Documento de Estrategia e Informe de la Comisión Europea sobre los progresos de cada uno de los países candidatos en vías de adhesión. 
disputa actual en Chipre, podría incluso solucionarla" (The Economist, 8 de septiembre de 2001). Sin embargo, de momento no se ha solucionado el problema $\mathrm{y}$ hay escasas esperanzas de que se solucione.

\section{Los avances económicos se han evaluado según si existen o no una economía de mercado y la capacidad de la UE de resistir sus fuerzas.}

\section{Criterios económicos}

Los progresos económicos se han evaluado con arreglo a los criterios económicos de Copenhague, es decir, a la existencia de una economía de mercado en funcionamiento y a la capacidad para resistir las fuerzas del mercado dentro de la UE. Chipre y Malta cumplen ambos criterios; la República Checa, Estonia, Letonia, Hungría, Lituania, Polonia, Eslovaquia y Eslovenia son también economías de mercado en funcionamiento y aunque haya algunas diferencias económicas importantes entre ellos y los Estados miembros, se prevé que a corto plazo podrán soportar la presión competitiva y las fuerzas de mercado dentro de la UE. Respecto de Bulgaria, la Comisión estima que es casi una economía de mercado en funcionamiento, aunque tiene algunas cuestiones pendientes. Rumania no cumple ninguno de los dos criterios pero, por primera vez, ha hecho progresos decisi- vos para alcanzar los objetivos. Con relación a Turquía se puede decir que no ha hecho avances hacia el logro de una economía de mercado en funcionamiento, especialmente debido a la reciente crisis. No obstante, parte considerable de su economía ya compite en el mercado de la UE.

Las negociaciones de los capítulos del acervo comunitario

Los días 11 y 12 de diciembre de 2002 se celebró el Consejo de Laeken donde se dio cuenta de la situación de los capítulos del acervo. La mayoría de los 29 capítulos están provisionalmente cerrados, aunque quedan cuestiones importantes por aclarar, como son la agricultura, la política regional y las previsiones financieras y presupuestarias, además el capítulo del transporte también presenta problemas, mientras que en los capítulos como competitividad, impuestos, o justicia y asuntos nacionales, muchos candidatos todavía están en negociaciones.

El plan es que la presidencia danesa el segundo semestre de 2002 pueda cerrar las negociaciones con los países candidatos. Si esto es posible, pese a la falta de incerteza en algunas cuestiones cruciales, la adhesión puede firmarse de tal manera de completar el 2003. En este caso, los primeros miembros podrían incorporarse en el 2004.

2. OTRAS CONSIDERACIONES ACERCA DE LA CONVERGENCIA Y LA ESTABILIDAD

Aunque los criterios de Copenhague lleguen a cumplirse a finales del 2002, en 
cuyo caso deben acelerarse mucho las negociaciones, posiblemente dejando cuestiones pendientes y aceptando que algunos países no cumplan totalmente los criterios. Esto no significa que el proceso de convergencia se haya desarrollado lo suficiente como para evitar las complicaciones que supondrá incluir estos países con todas sus divergencias, que de por sí son amplias en la UE.

La UE debe encarar el control de una UE de 27 candidatos, donde hay enormes divergencias, tanto económicas como sociales y culturales, donde la situación de un país afecta muy directamente al resto de países de la Unión. Por tanto, la entrada de países vulnerables económicamente y cuyas economías aún no son estables, significará que la Unión también será más inestable. Además, la ampliación aumenta el número de países con los que hay que negociar en el seno de la Unión, y, aunque ya se ha reformado el sistema institucional en el Tratado de Niza, de cualquier manera la toma de decisiones será difícil, debido a que hay más intereses en juego. Por esta razón, surgen opiniones que propugnan crear una UE dotada de más poder de decisión sobre los Estados miembros, y otras en virtud de las cuales los Estados miembros son los principales intérpretes. Aparecen así dos modelos, una Europa federal y la Europa de la unión de los Estados-nación. La primera opción es defendida por Alemania, lo que supondría la creación de un Gobierno europeo democrático, designado por el Parlamento y de un poder legislativo en que se otorguen mayores poderes al Parlamento; la segunda es defendida por Francia y Es- paña, que apuestan por la prolongación del modelo actual de Estados-nación, pero con cooperación entre los países, que podría perfeccionarse otorgando a la Comisión mayor protagonismo en la política exterior y de seguridad, pero manteniendo el derecho de veto en cuestiones clave. Lo que está claro es que se necesita tomar una decisión al respecto y aclarar qué camino se tomará ante la adhesión de los nuevos miembros, con el fin de evitar cualquier problema una vez producida la ampliación.

\section{Hay dos modelos: una Europa federal y la Europa de la unión de los Estados-nación.}

Aunque la UE reconoce la importancia estratégica de la ampliación desde el principio de la transición de los PECO, "en la práctica durante la última década no se ha seguido una estrategia clara" (Inotai, 2001). Aunque se hable de algunas fechas, no hay un calendario definido y las condiciones de la ampliación han sido aclaradas en la última parte de este período, y todavía no se han identificado cuáles serían los países que van a entrar en la primera adhesión. Los argumentos oficiales son que cualquier movimiento o cambio de fechas podría hacer más lenta la preparación de los países candidatos y así incrementar los efectos negativos en la estabilidad regional. Cualquier diferenciación prematura entre los países candidatos podría causar gran decepción entre los no admitidos, con el riesgo de crear países de segunda clase. De todas formas, 
los países esperaban empezar a negociar la adhesión en el año 2002, para acceder a la UE ya en el 2004. Si alguno de estos países, excepto Turquía que ya está fuera de esta primera oleada, quedase fuera, esto supondría un cierto grado de inestabilidad para la UE, pues habría decepción e inconformidad. Si por el contrario, se aceptasen los 12 países, debemos admitir que en un principio, la integración de demasiados países podría también dañar la cohesión de la UE en algunos puntos clave, ya comentados, como agricultura, financiación, y proceso de toma de decisiones.

Por tanto, aunque la ampliación de la Unión Europea puede contribuir notablemente a afianzar la estabilidad política, la democracia y el respeto por los derechos humanos en todo el continente europeo, así como a crear posibilidades de crecimiento, inversión y mayor prosperidad, no sólo para los futuros y actuales miembros, sino también para la comunidad internacional. Existen todavía también algunos riesgos, y algunos puntos débiles que pueden dañar la estabilidad de la Unión.

\section{LOS EFECTOS DE LA AMPLIACIÓN PARA OTROS PAÍSES}

\section{España}

La próxima ampliación traerá grandes consecuencias para el conjunto de la UE, y concretamente para España. Uno de los efectos más comentados y el que más temor provoca en España es el referente a la política de cohesión económica y social comunitaria, ya que los países de la próxima ampliación son países pobres y necesitan de elevados fondos comunitarios para realizar su convergencia. La cuestión es si este nuevo esfuerzo comunitario de convergencia se hará a costa de otros países también pobres dentro de la UE, por ejemplo España, Portugal y Grecia.

\section{La ampliación puede afianzar la estabilidad política del continente europeo, pero subsisten riesgos que pueden dañarla.}

Como hemos comentado en el apartado de las ayudas financieras, en las perspectivas del 2000-2006 la participación en los fondos de los actuales miembros todavía no ha cambiado mucho, y España no ha salido mal parada, a pesar de la reducción en algunas partidas. Pero, como es obvio, a la hora de fijar las perspectivas financieras de la Comunidad para el período 2007-2013, sobre las que deberá empezarse a discutir en el 2004 (año en el que se prevén las primeras adhesiones), España perderá una importante participación en los fondos estructurales. Si se siguen aplicando los actuales criterios, gran parte de las regiones que actualmente figuran como "Objetivo 1" (regiones con renta media por habitante inferior al $75 \%$ de la media comunitaria) dejarían de serlo, y sólo recibirán la ayuda Extremadura y Andalucía, mientras Galicia podría quedar dentro o fuera, según el ritmo de las adhesiones.

Es posible, además, que España quede fuera del Fondo de Cohesión, o que 
como máximo reciba algún tipo de fondo transitorio. La razón es que con la inclusión de los países candidatos, España rebasará el límite del $90 \%$ de renta media por habitante con respecto a la media europea. Por tanto, la ampliación de la UE tendría fuertes repercusiones en las ayudas financieras que recibe España hasta el momento, y por ese motivo, hay que empezar a instrumentar políticas nacionales capaces de enfrentar el problema.

La ampliación de la UE tendrá efectos en el comercio de todos los países de la Unión, debido al incremento de las relaciones comerciales entre las partes, pero el nivel de relaciones comerciales de España con estos países es inferior a la media de los países comunitarios. Las importaciones españolas de los PECO suponían una cuota cercana al $2 \%$ a finales de los 80 y en 1999 era de 4\%, mientras que en el mismo período las exportaciones se elevaron de un $1 \%$ a un $7,5 \%$. El temor que existe respecto del comercio con los PECO es que pueden ser competidores de España en las importaciones de otros países de la UE debido a que su patrón comercial es muy similar. En concreto, se temen las ventajas comparativas que pueden tener estos países, por ejemplo, un menor coste de la mano de obra, su elevada preparación, su proximidad a ciertos mercados europeos, etc. Al respecto, J. M. Jordán Galduf (2002) señala que la mayor parte de los efectos comerciales de la ampliación se han producido ya y, aunque ha habido una cierta aproximación en el patrón de comercio, no se compite exactamente en los mismos segmentos de precio y calidad en los mercados. De to- das formas, dice, resultaría muy conveniente reforzar las inversiones en capital humano y en tecnología, como vía para mantener la capacidad competitiva de España frente a los PECO.

\section{Se sostiene que la mayor parte de los efectos comerciales de la ampliación se ha logrado ya.}

Otro efecto que es necesario tener en cuenta antes de la ampliación es que la entrada de los PECO en la UE aumentará notablemente su capacidad de atraer inversiones. Ya hemos visto que la IED hacia estos países aumenta gradualmente. En España preocupa que estos países, debido a sus ventajas comparativas, desvíen una posible inversión cuyo destino sea ese país. Además, que esta inversión aumente la competitividad de estos países, haciéndolos por tanto fuertes competidores de la economía española.

\section{América Latina}

Los efectos de la ampliación en Latinoamérica no distan mucho de los vistos en España respecto del comercio y la inversión. Sin embargo, las relaciones económicas futuras entre América Latina y la Unión Europea dependen sobre todo de la reforma sostenida de la política económica latinoamericana y del papel de la Unión Europea en las negociaciones comerciales multilaterales y en las medidas de política exterior que se adopten en la Unión, más que de la ampliación de la Unión con el ingreso de nue- 
vos países. Sin embargo, la UE parece muy interesada en el mercado latinoamericano y se están celebrando acuerdos de asociación entre diversos países latinoamericanos, además, en su afán de promover el intercambio, la UE organiza reuniones, tales, como la Cumbre UE-América Latina y el Caribe celebrada en Madrid los días 16 y 17 de mayo de 2002.

\section{Países terceros mediterráneos} (PTM)

Las relaciones de la UE con los países del Mediterráneo se desarrolla en el contexto del Proceso de Barcelona de 1995, en el cual se celebraron acuerdos de cooperación en asuntos de política, seguridad y cooperación económica, que conducen al libre comercio y la cooperación en asuntos sociales y culturales. Actualmente, están en vigor acuerdos de asociación entre la UE y Marruecos, Túnez, Israel y la Autoridad Palestina. Se han firmado otros con Jordania y Egipto y se celebran negociaciones con Argelia, Líbano y Siria.

Es probable, al igual que en los casos anteriores, la ampliación afecte también las inversiones en los PTM, ya que dos de los principales intereses en estos países es su proximidad geográfica y el reducido coste laboral, dos puntos atractivos que también comparten los países candidatos, pero que en un futuro tendrán la ventaja adicional de pertenecer a la UE, por lo que se prevé una merma del flujo de IED hacia los PTM, al menos al principio de la integración.

\section{La ampliación podría afectar las inversiones en los terceros países del Mediterráneo.}

Estos países también enfrentarán el problema de la competencia comercial, pues en este caso, también existen bastantes similitudes en el patrón de las relaciones comerciales.

\section{Conclusiones}

A lo largo de este trabajo hemos visto que la ampliación de la UE tiene indudablemente efectos positivos, como el incremento de la estabilidad política con la aparición de nuevas democracias y el fortalecimiento de la paz, la seguridad, la justicia y el bienestar en Europa. También acarreará consecuencias económicas positivas en el sentido de que se creará una gran potencia mundial con gran capacidad de negociación a nivel internacional y capaz de enfrentar los retos de la globalización. Será un gran mercado de cerca de 480 millones de personas, lo que supone un incremento de las economías de escala, y la liberalización de los mercados permite una mejor asignación de recursos, el aumento del intercambio de bienes y servicios, tecnología y capitales. Esto favorecerá el desarrollo de los PECO pero este desarrollo se trasladará también a los actuales Estados miembros y facilitará el progreso de la UE en su conjunto.

Sin embargo, para lograr la mayor estabilidad posible es necesario que se pro- 
duzca la mayor convergencia posible entre los Estados miembros y la UE, y en este sentido todavía hay mucho por avanzar, quedan muchos puntos por cerrar en las negociaciones, y sobre todo, el nivel de ingresos de estos países siguen siendo muy reducido comparado con la media de la UE. Los flujos de capital, el movimiento de personas, la ayuda financiera, el intercambio de bienes, la transferencia de tecnología deberían ser capaces de reducir estas diferencias, y como hemos visto, ya se ha avanzado en gran medida en este sentido, excepto en el movimiento de personas que aún no se produce. Pero también hemos visto que, por ejemplo, las inversiones y el comercio se dirigen mayoritariamente hacia los países más desarrollados entre los candidatos, lo que a su vez les ayuda a desarrollarse más y a distanciarse de los demás. Actualmente la ayuda financiera se materializa a tra- vés de la ayuda a la preadhesión y a la integración en las perspectivas financieras del 2000-2006, pero estas últimas son todavía insuficientes para poder realizar todas las reformas que resta por hacer. Por tanto, por mucho que se haya avanzado en la convergencia queda aún camino por recorrer.

Por otro lado, debemos tener en cuenta que los países candidatos tienen especiales ventajas comparativas, como los salarios bajos, la preparación y el buen funcionamiento de la mano de obra y, como no, su proximidad a Europa. Son países que pronto avanzarán en la convergencia, que ganarán posiciones rápidamente, como ya lo están haciendo en el actual proceso de preadhesión. Por este motivo, es de esperar que, pese a sus riesgos, la ampliación, sea un paso adelante en la construcción de la UE.

\section{BiBLIOGRAFÍA.}

AHIJADO, A.; OSUNA, R. (1999). La ampliación al Este I. Teoría de la transición, hechos estilizados y el punto de vista comunitario. Madrid, Ed. Pirámide.

BRÚCKER, BOERI (2000). The impact of Eastern Enlargement on Employment and Labour Markets in the EU Member States. Berlín y Milán, Comisionado para el Empleo y los Asuntos Sociales. Consorcio para la Integración Europea.

CEPR. (1990). Monitoring European Integration. Londres, Ed. CEPR.

COMISIÓN EUROPEA. (2002, 30 de enero). Ampliación y Agricultura: una estrategia de integración a medida para los nuevos Estados miembros de la UE. Bruselas, IP/02/176.

-_-_-_-_-_-_-_-_- (2002, marzo). Explaining Enlargement. A progress Report on The Communication Strategy for Enlargement. DG Information Unit. . (2001, julio). La UE y la amplicación. Dirección General de Agricultura.

.Conseguir que la ampliación sea un éxito. (2002). Documento de estrategia e Informe de la Comisión Europea sobre los progresos de cada uno de los países candidatos en la vía de la adhesión.

Nota informativa. (2001, 6 de marzo). The free Movement of Workers in the Context of Enlargement.

COMMISSARIAT GÉNÉRAL DU PLAN. (1999). La ampliación de la UE al Este de Europa. Informe del Commissariat Général du Plan a la Asamblea francesa.Colecciones de Estudios Económicos, № 20 . 
CUADRADO ROURA, JR. (2001). "La política regional y la ampliación de la Unión Europea (20002006), consideraciones desde la óptica española”. En: Hacia dónde va Europa, págs. 230-251. Instituto de Estudios Económicos, $\mathrm{N}^{\mathrm{o}} 3$.

DE MELO, M.; DENIZER, C.; GELB, A. (1996). From Plan to Market: Patterns of Transition. Documento de trabajo $\mathrm{N}^{\circ}$ 1564, Banco Mundial.

DRYKER, D. A. (2001). “The Dynamic Impact on the Central-Eastern European Economics of Accesion to the European Union: Social Capability and Technology Absorption”. En: Europe-Asia Studies, Vol. 53, No 7, págs. 1001-1021, Carfax Publishing.

EUROSTAT. STATISTIC IN FOCUS. External Trade. The 13 Candidate Countries, Trade with the EU in 2000 .

2-3. (2002). The Evolution of FDI in Candidate Countries: Data 1995-2000. Tema

FISCHER, S.; SAHAY, R.; VEGH., A. (1998, abril). How far is Eastern Europe from Brussels? Documento de trabajo. FMI.

INOTAI, A. (2001, diciembre) Some reflections on Possible Scenarios for EU Enlargement. Institute for World Economics of the Hungarian Academy of Sciences. Working Paper, No 122.

IZQUIERDO LLANES, G. (2001). "Una revisión actual de la Unión Europea y de sus próximos retos". En: Hacia dónde va Europa, págs. 111-209. Instituto de Estudios Económicos, № 3.

JORDÁN GALDUF, J. M. (2001). “Análisis de los efectos de la ampliación de la UE para España”. En: Hacia dónde va Europa, págs. 212-227. Instituto de Estudios Económicos, № 3.

LUENGO, F. (2001). La Ampliación hacia el Este de la Unión Europea y los Procesos de Convergencia. Universidad Complutense de Madrid.

MADDISON, A. (1995). Dynamic Forces in Capitalism Development. A Long-run Comparative View. Oxford University Press.

NACIONES UNIDAS (2000, marzo) Replacement Migration: Is it a Solution to Declining and Ageing Population? Secretariado de las Naciones Unidas.

THE ECONOMIST. (2001, 17 de noviembre). "Expanding the European Union. The door creaks open”. . (2002, 9 de febrero). "Poland and Euopean Union". . (2001, 8 de septiembre). "The European Union and Cyprus. Crisis ahead". . (2001, 21 de julio). "Divided Cyprus. The danger of over-doggedness". . (2001, 1 de diciembre). "France and Enlargement".

WEISE, C.; J. BACHTLET, J.; DOWNES, R.; McMASTER, I.; TOEPEL, K. (2001, marzo). The impact of EU Enlargement on Cohesion. Berlín y Glasgow, German Institute for Economic Research y European Policies Research Centre. 


\section{Anexos}

Reparto de la IED en los países candidatos a la adhesión.

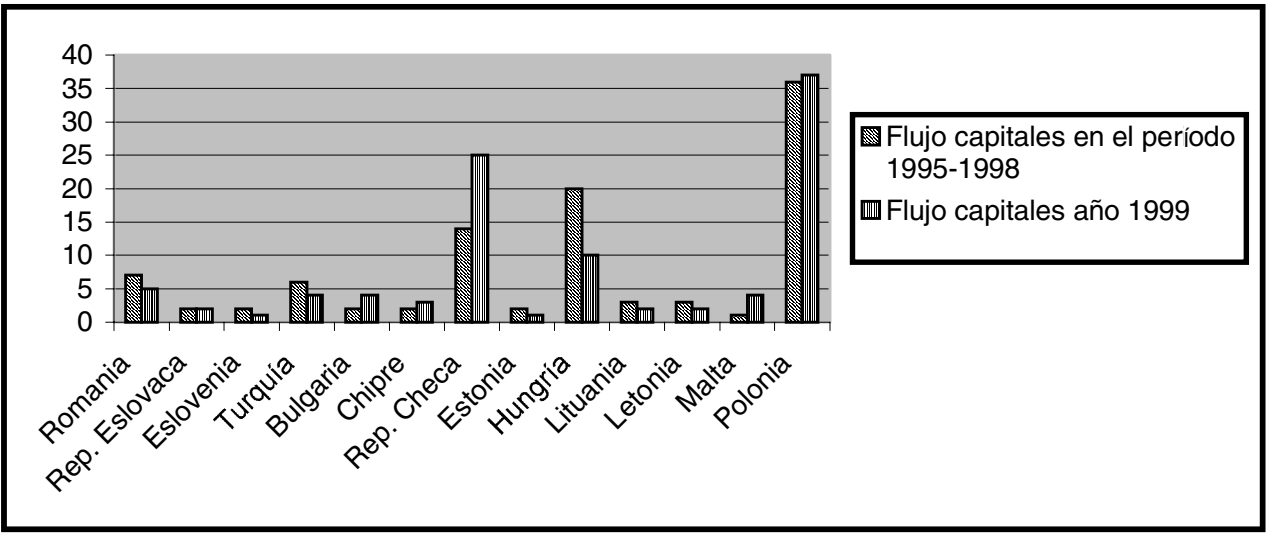

Fuente: EUROSTAT. Statistic in focus. 2002

Estimación de la migración potencial hacia los países EU-15 desde los países candidatos en condiciones de libre movimiento de trabajadores.

\begin{tabular}{|l|l|l|l|l|}
\cline { 2 - 5 } \multicolumn{1}{c|}{} & \multicolumn{2}{c|}{ CC8 emigrantes } & \multicolumn{2}{c|}{ CC10 emigrantes } \\
\cline { 2 - 5 } \multicolumn{1}{c|}{} & $\begin{array}{l}\text { Acumulado } \\
\text { despues de 10 } \\
\text { años }\end{array}$ & $\begin{array}{l}\text { Flujo por año } \\
\text { en los 10 } \\
\text { primeros años }\end{array}$ & $\begin{array}{l}\text { Acumulado } \\
\text { despues de 10 } \\
\text { años }\end{array}$ & $\begin{array}{l}\text { Flujo por año } \\
\text { en los 10 } \\
\text { primeros años }\end{array}$ \\
\hline $\begin{array}{l}\text { Sólo } \\
\text { trabajadores }\end{array}$ & 860.000 & $\begin{array}{l}70.000 \text { bajando } \\
\text { hasta 30.000 }\end{array}$ & 1.4 millones & $\begin{array}{l}120.000 \\
\text { bajando hasta } \\
50.000\end{array}$ \\
\hline $\begin{array}{l}\text { Todo tipo de } \\
\text { emigrantes }\end{array}$ & 1.8 millones & $\begin{array}{l}200.000 \\
\text { bajando hasta } \\
85.000\end{array}$ & 2.9 millones & $\begin{array}{l}335.000 \\
\text { bajando hasta } \\
145.000\end{array}$ \\
\hline
\end{tabular}

CC8: incluye República Checa, Hungría, Polonia, Eslovaquia, Eslovenia, Estonia, Letonia y Lituania. CC10: incluye, además, Bulgaria y Rumania.

Fuente: Brücker, Boeri (2000) 


\begin{tabular}{|l|c|c|c|}
\hline & Importac. & Exportac. & Saldo \\
\hline Bélgica & 4.6 & 6.5 & 1.8 \\
\hline Dinamarca & 2.2 & 2.2 & 0.0 \\
\hline Alemania & 50.6 & 57.4 & 6.8 \\
\hline Países Bajos & 1.8 & 2.5 & 0.7 \\
\hline España & 3.0 & 5.4 & 2.4 \\
\hline Francia & 9.7 & 14.9 & 5.2 \\
\hline Irlanda & 0.8 & 1.7 & 0.9 \\
\hline Italia & 13.3 & 20.4 & 7.1 \\
\hline Luxemburgo & 0.2 & 0.3 & 0.1 \\
\hline Holanda & 6.1 & 8.5 & 2.4 \\
\hline Austria & 9.4 & 10.1 & 0.7 \\
\hline Portugal & 0.8 & 0.5 & -0.3 \\
\hline Finlandia & 2.0 & 4.4 & 2.4 \\
\hline Suecia & 3.6 & 5.3 & 1.7 \\
\hline Reino Unido & 9.0 & 10.3 & 1.3 \\
\hline EU-15 & 117.0 & 150.0 & 33.3 \\
\hline
\end{tabular}

\begin{tabular}{|l|c|c|c|}
\hline & Importac. & Exportac. & Saldo \\
\hline Bulgaria & 3.1 & 3.2 & -0.1 \\
\hline Chipre & 1.0 & 3.1 & -2.1 \\
\hline Estonia & 3.2 & 3.3 & -0.1 \\
\hline Hungría & 21.9 & 23.0 & -1.1 \\
\hline Letonia & 1.9 & 2.0 & -0.1 \\
\hline Lituania & 2.2 & 2.6 & -0.4 \\
\hline Malta & 1.0 & 2.8 & -1.8 \\
\hline Polonia & 23.1 & 33.6 & -10.5 \\
\hline Rep. Checa & 21.4 & 23.8 & -2.3 \\
\hline Rumania & 7.6 & 8.7 & -1.1 \\
\hline Eslovaquia & 7.0 & 6.5 & 0.4 \\
\hline Eslovenia & 6.3 & 8.1 & -1.8 \\
\hline Turquía & 17.5 & 29.7 & -12.3 \\
\hline Total & 117.0 & 150.3 & -33.3 \\
\hline
\end{tabular}

Fuente: EUROSTAT. Statistics in focus. External Trade, 2000. 